\title{
Quantitative microstructural analysis of geological materials by atom probe: understanding the mechano-chemical behaviour of zircon
}

\author{
Julie M. Cairney ${ }^{1}$, Alexandre La Fontaine ${ }^{1}$, Patrick Trimby ${ }^{1}$, Limei Yang ${ }^{1}$, Sandra Piazolo ${ }^{2}$, \\ ${ }^{1}$ Australian Centre for Microscopy \& Microanalysis, University of Sydney, Australia \\ ${ }^{2}$ Australian Research Council Centre of Excellence for Core to Crust Fluid Systems/GEMOC, \\ Department of Earth and Planetary Sciences, Macquarie University, Australia
}

The mineral zircon $\left(\mathrm{ZrSiO}_{4}\right)$ is ideally suited for radiogenic dating of rocks. Not only does it contain trace amounts of uranium and thorium, enabling dating using radioactive decay in the $\mathrm{U}-\mathrm{Pb}$ system, but it is also a very robust mineral. It is generally believed to survive a range of geological processes such as erosion, deformation and high-grade metamorphism (up to 900 ${ }^{\circ} \mathrm{C}$ ). The spatial resolution for zircon dating using conventional techniques (e.g. sensitive high resolution ion microprobe (SIMS)) is in the range of 10-20 $\mu \mathrm{m}$, however several recent studies have suggested that zircons may not be as chemically robust as once believed, especially on the micron and sub-micron scale.

Atom probe tomography (APT) is a powerful microscopy technique that can provide 3D maps showing the position and atomic mass of individual atoms with sub-nanometre resolution [1]. It is ideal for studying the spatial distribution of atoms across small volumes (the total sample area is normally only a few hundred nanometres in size). Isotopic sensitivity is also an advantage for its application in the study of geological materials. It has recently been applied for the first time to $\mathrm{U} / \mathrm{Pb}$ isotope dating [2], where the results were found to agree well with SIMS.

Here, we will provide an overview of the technique of atom probe and present novel APT analyses of deformed zircons for comparison with previous studies of this material by electron backscatter diffraction (EBSD), cathodoluminescence (CL) and radiogenic U-Pb dating studies. EBSD analysis has revealed that these zircons show evidence of severe intracrystalline deformation, fracturing and grain size reduction as well as a large spread in $\mathrm{U}-\mathrm{Pb}$ ages. Low angle boundary networks that form up to $100 \mu \mathrm{m}$ wide deformation zones exhibit significant disturbances of the otherwise homogeneous CL signature. These regions of low angle grain boundary networks show moderate chemical resetting of the original ca. 900 Ma old zircons. [3].

Correlation of the disturbance of the $\mathrm{CL}$ signature and U-Pb derived ages with lattice distortions and grain boundaries has been interpreted to originate from accelerated lattice diffusion through the highly distorted crystal lattice. Such enhanced pipe diffusion would proceed at rates 1-3 orders of magnitude faster than the lattice diffusion in an undeformed lattice. Alternatively, fluid-mediated coupled dissolution and precipitation [4] or just precipitation of zircon in chemical equilibrium with a fluid at the time of deformation at low and high angle boundaries may result in presence of zircon with different chemistry. In the latter case, changes in chemistry and therefore time signature would occur instantaneously (in geological timescales).

Our atom probe analysis from distorted zircons shows the decoration of dislocations by Al suggesting that the chemical signature in zircon is indeed influenced by defects (Fig. 1b). Furthermore, APT reveals nanoscale zircon particles with distinctly different chemical signature in terms of $\mathrm{Al}$ and $\mathrm{H}$ content at high angle boundaries. The presence of such 
particles suggests rapid changes of zircon chemistry by fluid mediated precipitation and/or dissolution and precipitation.

In our paper, we will also present the results of ongoing studies of older samples, to discover whether lead displays similar segregation behavior, shedding new light onto the robustness of zircons for dating. We will also discuss the strengths and limitations of the technique of atom probe for the study of geological materials, describe our approach to the challenging issue of site-specific specimen preparation, and show the results of experiments designed to optimize the quality of the data obtained from zircon.

\section{References:}

[1] Gault, Moody, Cairney, Ringer, “Atom probe microscopy”, (Springer).

[2] Kelly and Larson, Ann. Rev. Mat. Sci., 2012, 42, p. 1.

[3] Piazolo, Austrheim, Whitehouse, American Mineralogist, 2012, 97, p. 1544.

[4] Putnis \& Putnis, 2007, J. Solid State Chem., 180, p. 1783.

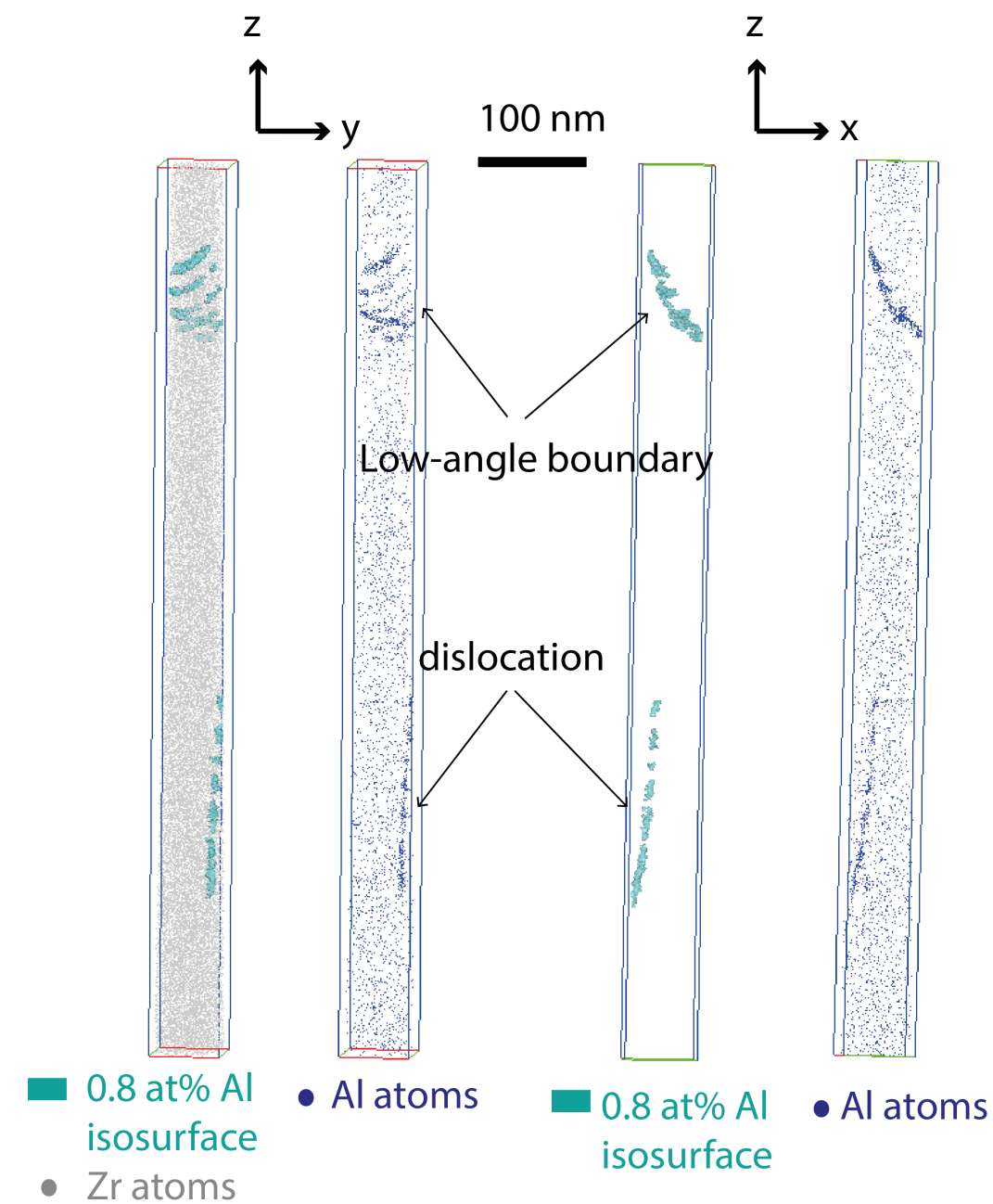

Figure 1. Atom probe tomography (APT) reconstructed volume of a distorted Zircon with a sub-grain boundary decorated with Aluminium with a 0.5 at. $\% \mathrm{Al}$ iso-concentration map. The dataset is shown from two different angles, so that the low angle boundary can be distinguished from the dislocation. 